
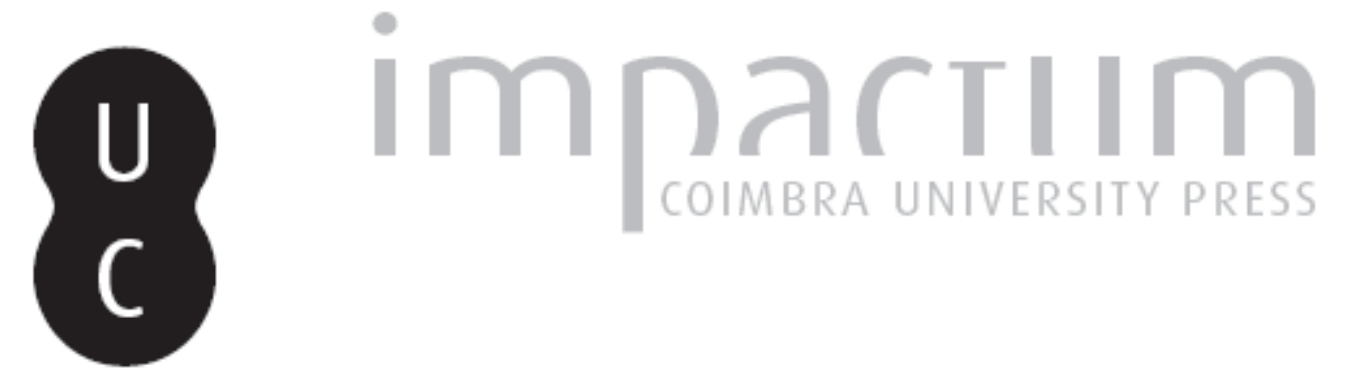

\title{
Laços entre a Faculdade de Letras e a Faculdade de Direito no século XX
}

\section{Autor(es): $\quad$ Marcos, Rui de Figueiredo}
Publicado por: Faculdade de Letras da Universidade de Coimbra, Instituto de História Económica e Social

URL

persistente:

URI:http://hdl.handle.net/10316.2/27898

DOI:

DOI:http://dx.doi.org/10.14195/0870-4147_42_6

Accessed : $\quad$ 26-Apr-2023 13:38:02

A navegação consulta e descarregamento dos títulos inseridos nas Bibliotecas Digitais UC Digitalis, UC Pombalina e UC Impactum, pressupõem a aceitação plena e sem reservas dos Termos e Condições de Uso destas Bibliotecas Digitais, disponíveis em https://digitalis.uc.pt/pt-pt/termos.

Conforme exposto nos referidos Termos e Condições de Uso, o descarregamento de títulos de acesso restrito requer uma licença válida de autorização devendo o utilizador aceder ao(s) documento(s) a partir de um endereço de IP da instituição detentora da supramencionada licença.

Ao utilizador é apenas permitido o descarregamento para uso pessoal, pelo que o emprego do(s) título(s) descarregado(s) para outro fim, designadamente comercial, carece de autorização do respetivo autor ou editor da obra.

Na medida em que todas as obras da UC Digitalis se encontram protegidas pelo Código do Direito de Autor e Direitos Conexos e demais legislação aplicável, toda a cópia, parcial ou total, deste documento, nos casos em que é legalmente admitida, deverá conter ou fazer-se acompanhar por este aviso.

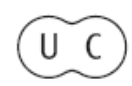





\title{
Laços entre a Faculdade de Letras e a Faculdade de Direito no Século XX
}

\author{
Rui de Figueiredo Marcos \\ Faculdade de Direito da Universidade de Coimbra
}

\section{Resumo:}

O estudo mostra o empenho e a influência que a Faculdade de Direito teve no modelo normativo que esteve na génese da Faculdade de Letras. Analisa o estreitamento progressivo das relações entre ambas as Faculdades ao longo do século XX, realçando o contributo dos grandes Mestres da História do Direito de Coimbra.

\section{Palavras chave:}

Faculdade de Letras de Coimbra; Faculdade de Direito de Coimbra; Primeira República; Reformas Universitárias; História do Direito.

\section{Abstract:}

The article explains the support and the influence of the Faculty of Law on the normative model that was the seed of the Faculty of Arts. Then, it considers the growing interconnection between both faculties along the $20^{\text {th }}$ century, emphasizing the role of Coimbra's outstanding History of Law Professors.

Keywords:

Faculty of Arts of Coimbra; Faculty of Law of Coimbra; First Republic; University reforms; History of Law. 
1. Muito antes de 1911, já a Faculdade de Direito expressara um voto radioso no sentido de que se criasse uma Faculdade de Letras no seio da Universidade de Coimbra. Diria mesmo, sem rebuço, que o nascimento da Faculdade de Letras correspondia a um velho anseio da Faculdade de Direito. O mais pletórico que se manifestou nos meios intelectuais da Alma Mater de então.

Escutemos a voz das fontes. No início do século XX, a Faculdade de Direito foi erigida como alvo de uma onda concertada de agressões. Umas vezes escondidas sob a capa do anonimato em folhas volantes, outras vezes, mais estrepitosas, ecoaram em jornais e, inclusive, no parlamento. Dentro dos muros agrestes da Faculdade de Direito, ainda enegrecidos pelo estilo fradesco do mobiliário, habitava, pretensamente, um ensino arcaico, bafiento e dogmático. As injustas declamações sonoras e os gestos desabridos de imprecação caíram aos pés da argumentação sólida inscrita na peça que Marnoco e Souza e Alberto dos Reis escreveram em defesa firme da Escola a que pertenciam ${ }^{1}$.

No meio de tamanha turbulência, depressa a Faculdade de Direito percebeu a necessidade de empreender uma reponderação global do seu magistério. O quietismo da Faculdade de Direito estava longe de ser verdadeiro. A Reforma de 1901 nem sequer lograra inteira execução e logo, no final do ano lectivo de 1906, a Faculdade dera sinais de que tencionava modernizar a organização do seu ensino. Designou, na altura, uma comissão composta pelos Doutores Guilherme Moreira, Marnoco e Souza e Machado Vilela².

Com enorme esmero e tendo como pano de fundo a imagem da internacionalização, seguiram-se cuidadosos lances preparatórios de uma futura reforma. Culminariam na Reforma dos Estudos Jurídicos de 1911, em que o governo da República se limitou a aprovar, na íntegra, a proposta oriunda da Faculdade de Direito de Coimbra ${ }^{3}$. Uma reforma de uma primorosa coerência que recebeu os maiores louvores dentro e fora do País.

Ora, foi precisamente no quadro dos alvitres reformistas de 1906 que relampejou de novo, agora de uma forma mais entusiástica e fundamentada, a proposta da criação de uma Faculdade de Letras na Universidade de Coimbra. Ao lado das Faculdades de Direito, Medicina e Ciências, uma Universidade digna desse

1 Ver Rui Manuel de Figueiredo Marcos, “A Primeira República e a Reforma dos Estudos Jurídicos na Faculdade de Direito de Coimbra”, in Boletim da Faculdade de Direito, vol. LXXXV (2009), pp. 57-59.

2 Ver Mário Júlio de Almeida Costa, O Ensino do Direito em Portugal no século XX, Coimbra, 1964, p. 25.

3 O projecto de reforma ficou a dever-se, em larga medida, ao labor e inquebrantável entusiasmo de Machado Vilela. Ver Rui Manuel de Figueiredo Marcos, Lembrança de Machado Vilela, Coimbra, 2002. 
nome devia possuir uma Faculdade de Letras. Neste sentido se pronunciaram expressamente os professores de Direito ${ }^{4}$.

Da instituição da Faculdade de Letras escorreriam, seguramente, préstimos valiosos para o ensino jurídico. No juízo da comissão de 1906, a Faculdade de Letras "poderia colaborar vantajosamente na educação dos alunos de direito com os seus estudos de história, de philosophia e de sociologia». Mesmo antes de nascer, adivinhava-se que a Faculdade de Letras viesse a ter um papel formativo essencial para os estudantes de Direito.

Muito conviria que a Faculdade de Letras de Coimbra esquadrinhasse um ano propedêutico para os alunos de Direito, à imagem do que já acontecia na Espanha e se reclamava na França. Destinar-se-ia a funcionar como uma espécie de introdução especial aos estudos jurídicos. Uma providência que se tornava tanto mais necessária quanto era certo que «os alumnos de direito trazem uma preparação muito deficiente dos lyceus, sendo excessivamente pobres e vagos os conhecimentos que elles possuem de história, philosophia e literatura» ${ }^{5}$. Uma debilidade secular que permanece.

O contributo da Faculdade de Letras para o ensino do Direito não se limitaria a assumir tão só o cariz preparatório ou ancilar num plano básico. Também os candidatos ao Doutoramento em Direito extrairiam valiosos benefícios do domínio de conhecimentos auxiliares da ciência jurídica. Aliás, este alvitre soou a premonitório, porquanto haveria de consolidar-se num preceito para os Doutoramentos inseridos no âmbito da secção de Ciências Jurídico-Históricas, quer fosse em Direito Romano, quer fosse em História de Direito ${ }^{6}$.

Em 1906, admitia-se, inclusive, a possibilidade de se estabelecerem cursos similares em ambas as Faculdades, de molde a aprofundar o estudo, sob ângulos diversos, das instituições jurídicas. Sinal ostensivo disso mesmo seria o acolhimento que, de bom agrado, os professores de Direito dispensariam àquilo que se apelidou de conferências mistas. Frequentadas por alunos de Direito e

4 Ver Marnoco e Souza e Alberto dos Reis, A Faculdade de Direito e o seu Ensino, Coimbra, França Amado, 1907, p. 151.

5 Ver Marnoco e Souza e Alberto dos Reis, A Faculdade de Direito e o seu Ensino, cit., pp. 151-152.

6 Perante o Conselho da Faculdade de Direito, na Congregação de 6 de Março de 1918, Paulo Merêa sustentou, em termos inequívocos, que o Doutoramento no grupo de História do Direito devia implicar a frequência obrigatória das cadeiras chamadas auxiliares da história na Faculdade de Letras. Mencionou, expressamente, as disciplinas de epigrafia e paleografia, diplomática e numismática, e a filologia, designadamente a filologia portuguesa, que reputava indispensável para o estudo conscencioso do direito português medieval. 
de Letras, estimulariam as investigações em comum ${ }^{7}$. Enfim, as vias de uma profícua colaboração entre a velha Faculdade de Direito e a futura Faculdade de Letras vislumbravam-se radiosas.

2. A Faculdade de Letras nasceu no ano da grande Reforma dos Estudos Jurídicos de 1911. Dir-se-ia que se tratou de uma simples coincidência. No entanto, julgo ser perfeitamente admissível sustentar a tese de que, em certos aspectos, a Faculdade de Direito de Coimbra influenciou o modelo genético da Faculdade de Letras. Ou, pelo menos, contribuiu para o entretecimento do pano de fundo da cultura reformista universitária de 1911, do qual emergiu a Faculdade de Letras.

$\mathrm{O}$ argumento não se apresenta de um intrigrante vislumbre. O Decreto de 18 de Abril de 1911 aprovou a reforma dos estudos jurídicos. O diploma que criou a Faculdade de Letras é o Decreto de 9 de Maio de 1911. A própria Faculdade de Direito de Coimbra reconheceu que o Decreto de 18 de Abril de 1911 traduziu a conversão em lei do projecto de reforma dos estudos jurídicos, votado unanimemente pelo Conselho da Faculdade em Congregação de 27 de Março de 1911 e, em seguida, apresentado ao Governo Provisório da República, o qual deu à Faculdade a subida honra de o aprovar quase integralmente ${ }^{8}$. Ora, se, em diversos aspectos, mais do que soluções paralelas, há verdadeiros decalques normativos entre o Decreto de 18 de Abril de 1911 e o Decreto de 9 de Maio de 1911, não custa admitir que o projecto saído da Faculdade de Direito de Coimbra constituiu uma fonte de inspiração para os arquitectos da Faculdade de Letras.

3. Importa fazer rebrilhar esses reflexos. A Primeira República abraçou o princípio da liberdade de espírito dos alunos. Em coerência, permitiu que se modificasse o regime legal das disciplinas que melhor quadrassem ao desenvolvimento da sua cultura jurídica.

Mas o que a Reforma de 1911 não ignorava é que subsistia entre as cadeiras uma filiação natural e uma sequência que se conservava prestimosa, para a qual muitos alunos não teriam ainda sensibilidade aferidora. Por isso, se impôs à Faculdade a obrigação de gizar um plano de estudos que, no seu

7 Neste sentido, ver Marnoco e Souza e Alberto dos Reis, A Faculdade de Direito e o seu Ensino, cit., p. 152.

8 É o que expressamente se reconheceu na Congregação de 1 de Junho de 1915 do Conselho da Faculdade de Direito de Coimbra. Ver A Universidade de Coimbra no Século XX. Actas da Faculdade de Direito (1911-1919), vol. I, introdução de Manuel Augusto Rodrigues, Coimbra, 1991, p. 194. 
superior entendimento, lhe parecesse o mais harmónico com a solidariedade e a sucessão lógica das diferentes disciplinas. Era um modo hábil de salvar a ideia de coerência integrante que, seguramente, entretecera o novo currículo da Faculdade de Direito de Coimbra.

Trilho idêntico seguiu a Faculdade de Letras. Segundo o artigo 6. ${ }^{\circ}$ do Decreto de 9 de Maio de 1911 que a fundou, não havia dependência legal e obrigatória entre as cadeiras e os cursos do quadro das disciplinas da Faculdade de Letras. Esta organizava, porém, a título de conselho, um plano de estudos, indicando a sucessão lógica das diferentes disciplinas, que julgou mais conveniente para o aproveitamento dos alunos 9 .

Quer a Faculdade de Letras, quer a Faculdade de Direito ofereciam, por conseguinte, um ensino segundo um plano aconselhado e não de acordo com um plano imposto. Abriram as portas aos percursos individualizados. No fundo, ambas as Faculdades anteciparam, quase de um século, o enorme alvoroço causado pela actual Reforma de Bolonha, na condição de pregoeira da geometria variável dos currículos e dos planos curriculares simplesmente aconselhados. Não raro, as ideias novas são as ideias velhas de que já nos esquecemos.

4. A Primeira República assinalou rumos metódicos claros ao ensino universitário. Agitaram-se categorias pedagógicas novas e fizeram-se opções sem tibiezas. Na concepção de lições magistrais que adoptou para o Direito, a Reforma de 1911 impunha aos professores que banissem das aulas a aridez inóspita do tradicional verbalismo abstracto. A apresentação dos princípios e institutos jurídicos de uma maneira apriorística e dogmática devia ceder a um ensino em que eles, preferencialmente, surgissem emoldurados na sua formação histórica e nas relações com a vida social. Procuravam-se, assim, desterrar as secas prelecções que cultivavam o puro género dogmático em tom pastoral.

O desenho metódico delineado para o magistério na Faculdade de Letras não podia exibir uma mais rematada concórdia com o Direito. No âmbito das lições magistrais em Letras, o ensino devia assumir, quanto possível, um carácter positivo e concreto, pela exemplificação de factos que ilustrassem as doutrinas e os princípios expostos ${ }^{10}$.

9 Isto é o que reza o artigo 7. . do Decreto de 9 de Maio de 1911. Corresponde, sem a mínima dúvida, ao artigo $9 .^{\circ}$ do projecto da autoria da Faculdade de Direito.

${ }^{10}$ Neste sentido se pronunciou o artigo 10..$^{\circ}$ do Decreto de 9 de Maio de 1911. O mesmo consta do artigo $15 .^{\circ}$ do projecto da Faculdade de Direito. 
O professor da Faculdade de Letras, além das exposições magistrais, podia dialogar com os alunos, «não formulando perguntas que pareçam ter o intuito de verificar se conhecem as doutrinas ensinadas, mas apenas para dar interesse às lições e despertar a iniciativa mental dos alunos» ${ }^{11}$. Assente no princípio da cooperação, a Faculdade de Letras e a Faculdade de Direito decretaram o diálogo novo, em que o professor não visava averiguar os conhecimentos do aluno, mas antes convocá-lo a cooperar no ensino, levando-o a pensar por si próprio e a acompanhar o raciocínio do professor. Desperto o espírito crítico, o aluno aprendia a observar os factos e a discutir as normas. Em sintonia ficou expressamente proibido, em Direito e nas Letras, o ditado como sistema de exposição e vedou-se a adopção oficial de quaisquer livros de texto para as lições ${ }^{12}$.

A adesão da Faculdade de Direito ao casemethod ou casesystem não se compadecia com a acção unilateral do professor. Tomado da Universidade de Harvard, radicava em assentar os princípios jurídicos sobre a análise de casos da jurisprudência. Saber ensinar implicava a recusa do ressequido monólogo que apenas convidava o estudante à passividade receptiva. No seu lugar, erguia-se, em gesto de emancipação intelectual do aluno de Direito e de Letras, a conclamada lição-diálogo.

5. Na visão de 1911, o ensino não devia exaurir a actividade de um docente. O universitário precisa sempre da investigação para fazer respirar o seu ensino. Uma teia científico-cultural e didáctica que se entretece de aquisições recíprocas. A este propósito, a Reforma de 1911 exibia uma cintilância bifronte. De um lado, expor a ciência feita e, de outro, mostrar como se faz a ciência.

As sementes sopradas de além-fronteiras voejaram até ao nosso país. Nas universidades alemãs, os seminários constituíram exemplos notáveis de progresso científico. O modelo dos seminários jurídicos passou à Itália e fez carreira na França, com as chamadas «salas de trabalho».

${ }^{11}$ Transcreveu-se o artigo 11. ${ }^{\circ}$ do diploma instituidor da Faculdade de Letras. A coincidência com a perspectiva da Faculdade de Direito mostra-se gritante. Até em termos literais. Na verdade, lê-se, expressis verbis, no artigo $16^{\circ}$ do projecto saído da Faculdade de Direito de Coimbra: «poderá o professor dialogar com os alunos sobre os factos e princípios que vai expondo, não para verificar se conhecem as doutrinas ensinadas, nem formulando perguntas que pareçam ter esse intuito, mas simplesmente para dar interesse às lições e despertar a iniciativa mental dos alunos».

${ }^{12}$ Revelam igual conteúdo normativo o artigo 12. ${ }^{\circ}$ do Decreto de 9 de Maio de 1911 e o artigo 20. ${ }^{\circ}$ do Decreto de 18 de Abril de 1911. 
$\mathrm{O}$ voto de alimentar a docência com a investigação surtiu estupendas consequências na Universidade de Coimbra. Para o Direito, a Reforma de 1911 transplantou o modelo estrangeiro, criando um estabelecimento congénere a que deu o nome de Instituto Jurídico ${ }^{13}$.

À sua imagem e semelhança, na Faculdade de Letras, passava a existir um Instituto de Estudos Históricos ${ }^{14}$. Ambos estavam destinados, em sintomático decalque legal, «a iniciar os estudantes nas investigações científicas» ${ }^{15}$. Assumiam todos os contornos de centros de actividade científica, considerados de suma utilidade a professores e a alunos. Aí se tenderia a implantar um ambiente de fervilhante debate de ideias ${ }^{16}$.

Os toques unissonantes entre a Faculdade de Letras e a Faculdade de Direito não ficavam por aqui. Apenas acrescentamos mais dois aspectos de perfeita comunhão. Um deles respeita à possibilidade de se criarem cursos livres, ou extraordinários, confiando a sua regência a prestigiadas individualidades estranhas ao corpo docente da Faculdade, ou, como a lei lhes preferiu chamar, notabilidades científicas nacionais ou estrangeiras ${ }^{17}$.

O que acabámos de salientar transporta-nos, recta via, ao segundo aspecto que não se pode omitir. Refere-se ao tema candente da formação dos professores de Letras e de Direito. Em palco argumentativo, esgrimiram-se duas correntes de opinião. Uma confiava na auto-formação do professor e no regime do livre-docentismo. Assim acontecia na Itália, onde, ao tempo, existiam cerca de dois mil privati docenti. Todavia, a condição do livre-docente, em vez de indicar um meio de formação, representava um simples título acrescido, quer para ingressar nas carreiras públicas, quer para conferir preferência no exercício de profissões liberais.

${ }^{13}$ Os trabalhos do Instituto Jurídico consistiam em exercícios, conferências e discussões científicas propícias ao domínio dos métodos de investigação. Do ponto de vista organizativo, o Instituto Jurídico integrava quatro secções, em harmonia perfeita com o mosaico dos grupos de disciplinas. Eis as quatro secções: a 1. a de História do Direito e de Legislação Civil Comparada,

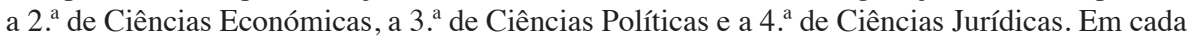
uma delas, surgiram dois tipos de cursos. Um era elementar, para principiantes. O outro, crismado de curso superior, destinava-se à preparação de estudos originais. Como apoio fundamental à missão que lhe foi assinalada, o Instituto Jurídico passava a dispor de uma biblioteca privativa.

${ }^{14} \mathrm{O}$ Instituto de Estudos Históricos também se encontrava dividido em secções. Eram três: a $1 .^{\text {a }}$ de Filologia, a $2 .^{\text {a }}$ de História e a $3 .^{\text {a }}$ de Filosofia.

${ }^{15}$ Basta confrontar o artigo $15 .^{\circ}$ do Decreto de 9 de Maio de 1911 com o artigo 32. ${ }^{\circ}$ do Decreto de 18 de Abril de 1911.

${ }^{16}$ A formulação legal que definia os trabalhos do Instituto de Estudos Históricos constitui uma cópia exacta da que se utilizou para o Instituto Jurídico.

${ }^{17}$ Ver o artigo $55 .^{\circ}$ do Decreto de 9 de Maio de 1911, cotejando-o com o artigo $82 .^{\circ}$ do Decreto de 18 de Abril de 1911. 
Foi, pois, sem espanto, que o Governo da Primeira República recusou o livre-docentismo com sistema geral de recrutamento dos professores de Letras e de Direito. À imagem de algumas universidades americanas, adoptou-se o outro sistema possível de recrutamento, o da assistência, que se baseava no princípio da formação oficial do professor. Mas com a promissora novidade da especialização. Especialização essa que começava logo à partida no concurso de provas públicas para assistente que se pautava de acordo com a divisão em grupos de disciplinas gizados para as Faculdades. Em Letras, por exemplo, havia seis grupos, para efeito dos concursos, a saber: Filologia Clássica, Filologia Românica, Filologia Germânica, História, Geografia e Filosofia ${ }^{18}$. A progressão na carreira, agora aferida por concursos documentais, conduziria aos postos cimeiros de professor extraordinário e de professor ordinário.

6. Não foi apenas à nascença que a Faculdade de Letras de Coimbra esteve ligada à Faculdade de Direito. Os laços estreitaram-se logo no seu primeiro sopro vital. Do lado da velha Faculdade Jurídica, isso ficou a dever-se, acima de tudo, aos professores de História do Direito.

Começou por instalar-se um frutífero intercâmbio científico que se manifestou nos periódicos das duas Faculdades. Na verdade, assistiu-se, durante as primeiras décadas do século XX, a uma significativa presença de contributos de professores de Letras no Boletim da Faculdade de Direito e de contributos de professores de Direito na Biblos - Boletim da Biblioteca da Faculdade de Letras da Universidade de Coimbra -, e na Revista Portuguesa de Históriapublicação do Instituto de Estudos Históricos Dr. António de Vasconcelos da Faculdade de Letras da Universidade de Coimbra.

Eis uma breve ilustração. Inaugurou a participação dos professores da Faculdade de Letras no Boletim da Faculdade de Direito um dos seus maiores ornamentos, como então se usava dizer. Aludimos a António de Vasconcelos que, em 1917, aí publicou um estudo de incidência histórico-jurídica, intitulado Origens do fôro académico na antiga universidade portuguesa ${ }^{19}$. Numa nota absolutamente invulgar, a Comissão Redactora do Boletim, composta por Alberto dos Reis, Caeiro da Mota e Carneiro Pacheco, exarou um agradecimento «pela colaboração com que o honra, ao ilustre professor Dr. António Garcia

${ }^{18}$ Neste sentido, ver o artigo $3 .^{\circ}$ que se aplicava por força remissiva do artigo $49 .^{\circ}$ do Decreto de 9 de Maio de 1911.

${ }^{19}$ Foi acabado de redigir na Quinta do Montalegre (Oliveira do Hospital), em 21 de Setembro de 1917. 
Ribeiro de Vasconcelos, eminente Director da Faculdade de Letras e do Arquivo da Universidade de Coimbra ${ }^{20}$

Para além do seu primeiro Director, um outro destacado vulto da Faculdade de Letras de Coimbra inscreveu o seu nome nos anais do Boletim da Faculdade de Direito. Em mente temos Manuel Gonçalves Cerejeira que, em 1925, aí dissertou sobre os ordenados dos lentes da Universidade ${ }^{21}$. Em 1949, seria a vez de Albin Eduard Beau discorrer a respeito da Escola Peninsular do Direito Natural, abordando o conceito e a função de Imperium em Francisco Suárez ${ }^{22}$. Também com raízes na Faculdade de Letras de Coimbra, não se podem esquecer os importantes estudos de Joaquim Veríssimo Serrão no Boletim da Faculdade de Direito, em que curou de temas muito da sua predilecção: o humanismo jurídico, o método cujaciano e o seu enorme expoente António de Gouveia, e as fontes de direito para a história da sucessão de Portugal, com uma aprofundada incursão na crise dinástica de $1580^{23}$.

Da Faculdade de Letras da actualidade, distinguiram o Boletim da Faculdade de Direito Maria Helena da Cruz Coelho, com um proficiente estudo dedicado aos interditos e às infracções económicas no período da formação de Portugal ${ }^{24}$, e recentissimamente, uma sua figura cimeira, Maria Helena da Rocha Pereira, ofereceu, ao periódico da Faculdade de Direito, páginas imperecíveis sobre as raízes clássicas da União Europeia. Deixaremos de fora outras expressões deste intercâmbio cultural, por se encontrarem desprovidas de dimensão institucional. Em gesto de homenagem, constitui para mim um imperativo lembrar, no ano da sua morte que coincidiu com o centenário da Faculdade de Letras, o belíssimo prefácio que Aníbal Pinto de Castro escreveu para o livro de Rui Manuel de

${ }^{20}$ Ver António de Vasconcelos, "Origens do foro académico na antiga universidade portuguesa”, in Boletim da Faculdade de Direito, ano III (1916-1917), p. 404.

${ }^{21}$ Ver Manuel Gonçalves Cerejeira, "Notas sobre os ordenados dos lentes da Universidade", in Boletim da Faculdade de Direito, ano IX (1925-1926) pp. 9 e ss.

${ }^{22}$ Ver Albin Eduard Beau, "O conceito e a função do Imperium em Francisco Suárez", in Boletim da Faculdade de Direito, ano XXV (1949), pp. 47 ss.

${ }^{23}$ Joaquim Veríssimo Serrão, "António de Gouveia e a prioridade do método cujaciano do Direito; "António de Gouveia e o seu tempo (1510-1566)"; "Fontes para a história da sucessão de Portugal" e "Os juristas de França e a crise dinástica de 1580", in Boletim da Faculdade de Direito, vol. XXVIII (1952), pp. 181 e ss.; vol. XLII (1966), pp. 25 e ss., vol. XLIII (1967), pp. 1 e ss.; vol. XXXV (1959), pp. 92 e ss.; e vol. XXXIV (1958), pp. 19 e ss., respectivamente.

${ }^{24}$ Ver, respectivamente, Boletim da Faculdade de Direito, vol. LXXVII (2001), pp. 33 ss; e vol. LXXXIV (2008), pp. 11 ss. 
Figueiredo Marcos, Eça de Queirós, a Europa e a Faculdade de Direito de Coimbra no Século XIX ${ }^{25}$.

7. Num sentido inverso, encontram-se abundantes colaborações de professores de Direito inscritas no rútilo periodismo da Faculdade de Letras de Coimbra. Surgem, inclusive, na qualidade destacada de membros da Redacção da Revista Portuguesa de História. E desde o seu número inaugural. Foram os casos de Paulo Merêa e de Luís de Cabral de Moncada. Seguiram-se Guilherme Braga da Cruz e Mário Júlio de Almeida Costa ${ }^{26}$.

A participação mais assídua pertence, de modo incomparável, a Paulo Merêa, quer na Biblos, quer na Revista Portuguesa de História. A justo título, mereceu, nesta última, nada menos do que três volumes de homenagem que se estenderam por cinco anos ${ }^{27}$.

$\mathrm{Na}$ Biblos, inscreveu, principalmente, estudos de elevado apuro filológico. Uma faceta do espírito de Paulo Merêa que, no acerto de Torquato de Sousa Soares, «o levaria a versar com grande originalidade temas de semântica jurídica, sobre que nos legou considerações tão subtilmente reveladoras que bem podemos dizer ter resolvido definitivamente problemas que até aí se apresentavam de difícil solução» ${ }^{28}$. Mencionam-se Sobre a palavra Manda, Sobre a palavra Angueira, Para um glossário do nosso Latim Medieval, De Portucale (civitas) ao Portugal de D. Henrique, Nótulas filológicas, Menendus $=$ Ermenegildus e Dois problemas filológico-jurídicos ${ }^{29}$.

Não menos imponente foi a presença de Paulo Merêa nas páginas da Revista Portuguesa de História ${ }^{30}$. Com os requintes de genialidade que sempre o acompanharam, versou temas tão diversos como, por exemplo, as origens

${ }^{25}$ Foi dado à estampa com uma versão inglesa Eça de Queirós, Europe and the Coimbra Faculty Law in the 19th Century, Coimbra, Almedina, 2005.

${ }^{26} \mathrm{Na}$ condição de membros do conselho redactorial, aparecem logo no tomo I, em 1940, Paulo Merêa e Cabral de Moncada. Em 1947, entra Guilherme Braga da Cruz, ingressando Mário Júlio de Almeida Costa em 1959.

${ }^{27}$ Correspondem ao tomo XII, vol. I (1969), ao tomo XIII, vol. II (1971), e ao tomo XIV, vol. III (1974).

${ }^{28}$ Ver Torquato de Sousa Soares, "Quatro colaboradores Mestres de Superior Quilate", in Revista Portuguesa de História, tomo XVIII (1980), p. 344.

${ }^{29}$ Consultar, respectivamente, Biblos, vol. XII (1936), pp. 151 ss.; vol. XVI (1940), pp. 55 ss., e 623 ss., vol. XVII (1941), pp. 357 ss., e 747 ss.; vol. XIX (1943), pp. 45 ss.; vol. XXI (1945), pp. 243 ss.

${ }^{30} \mathrm{O}$ consagrado periódico da Faculdade de Letras muito beneficiou do estímulo e conselho de Paulo Merêa e, evidentemente, de Damião Peres. Foi Torquato de Sousa Soares quem expressamente o reconheceu. 
do concelho de Coimbra, Conventus Nobilium, os territórios portugueses no século $\mathrm{XI}^{31}$, o Tratado de Tui de 1137 do ponto de vista jurídico, a Aclamação dos nossos reis, e Portugal no século $\mathrm{X}^{32}$.

Paulo Merêa haveria ainda de transformar-se em pólo aglutinador da participação de três outros grandes vultos da Faculdade de Direito na Revista Portuguesa de História. Em sua homenagem, aí escreveram Cabral de Moncada, Guilherme Braga da Cruz e Mário Júlio de Almeida Costa. O primeiro, de modo cintilante, esboçou o perfil de Paulo Merêa. Por seu turno, Braga da Cruz dedicou-lhe o estudo mais erudito que alguma vez compôs, intitulado O direito subsidiário na história do direito português. E Mário Júlio de Almeida Costa, sentindo vivo empenho que uma recordação da sua prova para professor catedrático ficasse arquivada num volume de homenagem «ao venerando sábio Paulo Merêa», legou ao futuro a sua belíssima Adopção na história do direito português. ${ }^{33}$

O cruzamento de gestos de homenagem através de artigos científicos constituiu um profícuo campo de relacionamento entre Letras e Direito. É disso mesmo ilustrativo Mulher Recabdada. Uma investigação que Paulo Merêa fez publicar na Miscelânea de Estudos em Honra de Carolina Michaëlis de Vasconcelos $^{34}$. No domínio das Letras, era considerada, segundo Gonçalves Cerejeira, «a mulher mais sábia do mundo» ${ }^{35}$. Se percorrermos o rumo inverso, encontram-se, no volume de homenagem conjunta a Paulo Merêa e a Guilherme Braga da Cruz, as cintilantes participações de Américo da Costa Ramalho, Manuel Augusto Rodrigues, Maria Helena da Rocha Pereira e Torquato de Sousa Soares ${ }^{36}$.

Não me deterei nas abundantes recensões elaboradas, quer por professores de Letras a obras de mestres da Faculdade de Direito, quer por professores de Direito a obras de mestres da Faculdade de Letras. Dou apenas o rútido exemplo

${ }^{31}$ Importa sublinhar que este estudo foi elaborado com o Doutor Amorim Girão.

${ }^{32}$ Ver Revista Portuguesa de História, respectivamente, tomo I (1941), pp. 49 ss.; tomo II (1943), pp. 255 ss., e 305 ss.; tomo X (1962), pp. 411 ss.; e tomo XI (1964-1968), pp. 144 ss.

${ }^{33}$ Ver Revista Portuguesa de História, tomo XII, vol. I (1969), pp. V-XI, e 95-120; e tomo XIV, vol. III (1974), pp. 177-316.

${ }^{34}$ Ver Paulo Merêa, Estudos de História do Direito. I- Direito Português, Lisboa, Imprensa Nacional, 2007, pp. 163 e segs.

${ }^{35}$ M. Gonçalves Cerejeira, "Os Novos Mestres. A Senhora D. Carolina Michaëlis de Vasconcelos", in Biblos, vol. I (1925), p. 7.

${ }^{36}$ Consultar "Estudos em Homenagem aos Profs. Doutores M. Paulo Merêa e G. Braga da Cruz II", in Boletim da Faculdade de Direito, vol. LVIII (1982), pp. 297 e ss., 569 e ss., 827 e ss., e 1025 e ss. 
da apreciação que Cabral de Moncada fez do livro de autoria de Albin Eduard Beau, Die Entwicklung des portugiesischen Nationalbewusstseins ${ }^{37}$.

8. Outros palcos houve em que se levaram à cena peças que, na Universidade de Coimbra, retrataram a proximidade da Faculdade de Letras à Faculdade de Direito. Desde logo o Doutoramento Honoris Causa que a Faculdade de Letras concedeu a Paulo Merêa, em $1948^{38}$. «Nunca ninguém o terá merecido tanto, nesta casa, que tanto honrou». Não podiam ser mais eloquentes estas palavras escritas por Torquato de Sousa Soares na altura da jubilação de Paulo Merêa ${ }^{39}$ A subida distinção não se apresentava dissociável do enorme prestígio que Paulo Merêa conquistara durante o período em que regeu a cadeira de História de Portugal na Faculdade de Letras de Coimbra. Entre os seus discípulos contaram-se sete ilustres professores da Faculdade de Letras. Da secção de Ciências Históricas, Lopes de Almeida e Torquato de Sousa Soares. Da secção de Ciências Filosóficas, Sílvio Lima. Da secção de Filologia Românica, Paiva Boléo e Costa Pimpão. Da secção de Filologia Germânica, Gonçalves Rodrigues e Paulo Quintela ${ }^{40}$. Não podemos ainda omitir o nome de Vitorino Nemésio.

Pretendendo, em 1959, assinalar a sua jubilação, um outro professor de Direito viu-se elevado a Doutor Honoris Causa pela Faculdade de Letras de Coimbra. Alude-se a António de Oliveira Salazar, presidente do Conselho de Ministros ${ }^{41}$. Na proposta de atribuição do grau saída da Faculdade de Letras, avultam dois traços quase esquecidos do retrato académico de Salazar. E bem relevantes para o tema que nos ocupa. Um deles é que a Faculdade de Letras o contara entre os seus escolares. Em segundo lugar, lembrava-se o facto de, havia mais de trinta anos, alguns dos futuros professores de Letras assistirem com a permissão do

37 Trata-se de um estudo sobre a génese e evolução da consciência nacional portuguesa. Consulte-se o Boletim da Faculdade de Direito, vol. XX (1944), pp. 665 e ss.

${ }^{38}$ Ver Fernando Aguiar-Branco, Doutores Honoris Causa em Letras de 1926 a 2001, Sinopse das suas Biografias, Porto, 2002, pp. 170-171.

${ }^{39}$ Ver Torquato de Sousa Soares, "Prof. Doutor Manuel Paulo Merêa", in Biblos, vol. XXIV (1948), p. 539.

${ }^{40}$ Do excepcional ambiente que rodeava o magistério de Paulo Merêa dá-nos conta o vibrante testemunho do professor Manuel Lopes de Almeida: «Muito poucas vezes se terão aliado e manifestado num curso público universitário tão clara inteligência e tanto espírito compreensivamente crítico. À vivacidade da exposição juntava-se o conhecimento profundo da matéria versada, e uma e outra, dominados pelo entusiasmo e pelo amor do assunto, trespassava-os o Mestre eminente aos seus discípulos, que os havia ali capazes de o ser mais que em pura atitude discente».

${ }^{41}$ Recorda-se que Oliveira Salazar, embora convidado a dar a sua lição jubilar na Universidade de Coimbra, agradecera, mas declinara o convite. 
Mestre da Faculdade de Direito, às suas lições de economia social ${ }^{42}$. Uma prova evidente do interesse que certas matérias ensinadas na Faculdade de Direito despertavam nos estudantes de Letras.

Não menos ficaram indelevelmente impressos nas memórias douradas de ambas as instituições os múltiplos doutoramentos solenes da Faculdade de Letras, em que intervieram, na condição de paraninfos, mestre de Direito de Coimbra. Na década de quarenta do século XX, importa mencionar as cerimónias de imposição de insígnias a Albin Eduard Beau e a Delfim Santos. O primeiro teve como padrinho o então director da Faculdade de Direito e eminente penalista, Doutor José Beleza dos Santos. Fez rebrilhar os seus méritos o ilustre professor de Letras, Torquato de Sousa Soares ${ }^{43}$. Foi apresentante do segundo, o Doutor Luís Cabral de Moncada ${ }^{44}$. Uma justa eleição. Acompanhava o seu afilhado, nas palavras de Sílvio Lima, enquanto «ardoroso cultor do germanismo filosófico» ${ }^{45}$.

A Cabral de Moncada caberia ainda a distinção de ser, em 1951, padrinho do filólogo romanista Joseph Maria Piel. Na altura, ressaltou as suas benemerências de restaurador da filosofia do direito em Portugal o Doutor Miranda Barbosa ${ }^{46}$.

Sem registo aqui não podem ficar também os Doutoramentos honoris causa em Letras de Júlio Dantas, Presidente da Academia das Ciências de Lisboa, de Giovanni Spadolini, Presidente do Senado da República Italiana e antigo Primeiro-Ministro de Itália, e de Fernando Aguiar-Branco, mecenas e Presidente da Fundação Eng. António de Almeida ${ }^{47}$. É que em todos eles voltaram a surgir mestres de Direito. E, de novo, envergando as vestes ataviadas de afiançadores. Aludimos aos insignes professores Fernando Andrade Pires de Lima ${ }^{48}$, Rui de Alarcão e Francisco Manuel Pereira Coelho ${ }^{49}$.

9. Do panorama esboçado ressalta, a todas as luzes, que a consolidação dos elos científicos entre as duas prestigiosas Faculdades da Universidade de

${ }^{42}$ Ver Biblos, vol. XXXV (1959), p. 669.

${ }^{43}$ Ver Biblos, vol. XX (1944), pp. 537-541.

${ }^{44}$ Pertenceu ao Doutor Manuel de Paiva Boléo o elogio do insigne mestre de Direito.

${ }^{45}$ Ver Biblos, vol. XX (1944), p. 564.

${ }^{46}$ Ver Biblos, vol. XXVIII (1951), pp. 475-490.

47 Tais cerimónias solenes ocorreram em 1955, 1991 e 2001, respectivamente.

${ }^{48}$ Proferiu o elogio de Pires de Lima, então Ministro da Educação Nacional, o Doutor Miranda Barbosa. Ver Biblos, vol. XXXI (1955), pp. 430 e ss.

${ }^{49}$ Os professores da Faculdade de Letras Maria Alegria Fernandes Marques e Maria Luísa Portocarrero Silva pronunciaram os discursos laudatórios, respectivamente, de Rui de Alarcão e de Francisco Pereira Coelho. Ver Biblos, vol. LXVIII (1992), pp. 596-600; e Fernando Aguiar-Branco, Doutores Honoris Causa em Letras, cit., pp. 112 e ss. 
Coimbra muito ficou a dever aos grandes mestres de História do Direito, em especial, a Paulo Merêa. Nada mais justo do que, na comemoração do centenário da Faculdade de Letras, avivar a sua lembrança.

Acompanhando as reformas que moldaram a relevante evolução do ensino do direito no século XX, a Faculdade de Direito de Coimbra emprestou ao magistério histórico-jurídico um constante sopro renovador. Marcou o seu início a proeminente figura de Paulo Merêa. Logo em 3 de Agosto de 1914, o Conselho decidira apresentá-lo ao governo para ser nomeado professor extraordinário de Ciências Históricas. Apesar dos valiosos contributos de Guilherme Alves Moreira $^{50}$ e de José Caeiro da Mata quando, durante algum tempo, estiveram na docência de disciplinas históricas ${ }^{51}$, pertenceu a Paulo Merêa o impulso decisivo na modernização da ciência da história do direito português.

Já no estudo de juventude que, em 1913, o revelou ao mundo jurídico, Paulo Merêa patenteava os notáveis atributos que o viriam a consagrar. Reagindo contra um exagerado fervor positivista e seduzido pelo renascimento do idealismo, lastimava o tempo em que o homem se afastara da filosofia para se recolher em absoluto à contemplação da ciência. Uma via demasiado estreita da qual naturalmente emergiu a avidez por um pensamento filosófico que, a despeito de tudo, não prescindisse do contacto com a realidade viva, ou, na frase de Boutroux que Merêa sabiamente convocou, uma filosofia que representasse o legítimo produto de uma colaboração do espírito com as coisas ${ }^{52}$.

Daí em diante, Merêa construiu uma obra monumental, repartida entre a história das instituições e a história do pensamento jurídico. Aliou à fria severidade filológica dos textos a preocupação de emoldurar sempre a análise dos problemas histórico-jurídicos com os seus laços culturais, de molde a proporcionar explicações panorâmicas de conjunto. Versou Paulo Merêa um assombroso rol de temas. Cruzou, sem repouso, as áreas da história do direito

${ }^{50}$ Acerca do zelo posto por Guilherme Moreira na renovação dos primeiros períodos do direito peninsular e do papel pioneiro que assumiu na difusão entre nós, tanto da obra do grande historiador Eduardo de Hinojosa, como das investigações de Karl Zeumer respeitantes à legislação visigótica, ver, por todos, Guilherme Braga da Cruz, A Revista da Legislação e de Jurisprudência, Esboço da sua História, vol. I, Coimbra, 1975, pp. 431 e ss., em especial, nota 1051, pp. 433 e ss. No tocante à copiosa produção de Hinojosa, consultar José Maldonado, "Eduardo de Hinojosa y la historia del Derecho”, in Arbor, tomo XIV (1949), pp. 385 e ss, particularmente, pp. 388 e ss.

51 José Caeiro da Mata (1877-1963) rumou à Faculdade de Direito de Lisboa em 1919, tendo sido mesmo Reitor da Universidade de Lisboa a partir de 1929. Da sua passagem pelo magistério da história em Coimbra, conhecem-se umas lições. Vide Caeiro da Mata, História do Direito Português (exposição reunida por António Godinho e Francisco Caeiro), Coimbra, 1912.

${ }^{52}$ Vide Manuel Paulo Merêa, Idealismo e Direito, Coimbra, 1913, pp. 30 e ss. 
privado e da história do direito público, para além de múltiplas incursões coroadas de êxito ao pensamento político nacional e europeu. Teve ainda o mérito de nos legar diversas sínteses expositivas da história do direito português ${ }^{53}$. Não há réstia de exagero na afirmação de que foi Merêa o criador de uma verdadeira escola de história do direito, cuja influência não se confinou às fronteiras do nosso país ${ }^{54}$.

Contemporâneo de Merêa, Luís Cabral de Moncada revelou-se também um insigne historiador do direito, se bem que o seu compromisso de alma o tivesse conduzido preferencialmente à filosofia do direito ${ }^{55}$. Uma ligação, aliás, que por si só explica o sólido arrimo filosófico com que abordou a compreensão da história do direito ${ }^{56}$ e o seu específico problema metodológico ${ }^{57}$.

Todavia, o verdadeiro continuador do trilho aberto por Paulo Merêa foi, sem dúvida, Guilherme Braga da Cruz. Apresentou-se a doutoramento, em Novembro de 1941, defendendo uma dissertação que versava o direito de troncalidade. Lançou, então, a primeira pedra de uma extensa obra, com um primoroso estudo jurídico do princípio troncal, onde não se esquecia de dedicar uma enorme atenção a dois institutos que lhe estavam relacionados pelo fundamento histórico e sociológico que os inspirava: o retrato familiar e a reserva hereditária ${ }^{58}$.

${ }^{53}$ Saídas do proficiente magistério de Paulo Merêa, existem diversas lições que começaram a surgir em 1922. As últimas conhecidas são os Elementos da História do Direito Português (prelecções compiladas por Araúuo Barros), Coimbra, 1938.

${ }^{54}$ Registe-se, nomeadamente, o estudo de Paul Ourliac, "Ce que l'histoire du droit doit à Paul Merêa et à G. Braga da Cruz”, in Boletim da Faculdade de Direito - Estudos em Homenagem aos Profs. Doutores M. Paulo Merêa e G. Braga da Cruz - 1, vol. LVIII (1982), pp. 771 e ss.; também Mário Júlio de Almeida Costa, "Lembrança de Paulo Merêa, Lembrança de Braga da Cruz”, in Boletim da Faculdade de Direito, vol. LXXX (2004), pp. 3 e ss.; e Rui de Figueiredo Marcos, "Um Relance a Propósito de Dois Volumes de Estudos de Paulo Merêa”, in Prelo, vol. I (2006), pp. 80 e ss.

${ }^{55}$ A respeito de Cabral de Moncada, consultar, entre outros, António Braz Teixeira, "Sobre a Filosofia Jurídica de Cabral de Moncada" in Caminhos e Figuras da Filosofia do Direito Luso-Brasileira, Lisboa, 1991, pp. 75 e ss.; Erik Jayme, "Luís Cabral de Moncada (1888-1974)e as suas Relações com a Alemanha” in Boletim da Faculdade de Direito, vol. LXIX (1993), pp. 233 e ss.; Mário Bigotte Chorão, "Um Jusfilósofo Português da Contemporaneidade", in O Direito, n..$^{\circ} 121$ (1989), pp. 315 e ss.

${ }^{56}$ No essencial, o produto das investigações histórico-jurídicas de Cabral de Moncada encontra-se reunido nos seus Estudos da História do Direito, vols. I, II e III, Coimbra, 1948/1950; e também nos vols. I e II, Coimbra, 1958/1959.

${ }^{57}$ Pelo que respeita à obra de Cabral de Moncada na esfera do ensino do direito romano, ver Gonçalo de Sampaio e Melo, vol. I, Lisboa, 1991, pp. 310 e ss.

${ }^{58}$ Vide Guilherme Braga da Cruz, O Direito de Troncalidade e o regime jurídico do património familiar, tomo I, Braga, 1941. O tomo II - A Exclusão Sucessória dos Ascendentes, Braga, 1947, 
Depois, ao longo de uma vida de infatigável labor, cultivou um considerável espectro de temas, inscritos no direito antigo e medieval, mas também nos alicerces do direito português moderno ${ }^{59}$. Uma produção que ostenta um extraordinário apuro científico. Senhor de uma grandeza moral e de uma estatura intelectual que fizeram dele o símbolo do homem universitário do seu tempo, Braga da Cruz deixou impressos na lembrança de todos quantos o conheceram os contornos de uma personalidade ímpar ${ }^{60}$.

É Mário Júlio de Almeida Costa o discípulo directo e dilecto de Braga da Cruz. Tal como o seu Mestre, prosseguiu a renovação da ciência histórico-jurídica, quer no plano da docência, quer no campo da investigação ${ }^{61}$. Começou por se embrenhar no direito institucional medievo, de que constituem uma subida expressão as dissertações que o guindaram à cátedra de História do Direito em Coimbra $^{62}$. Não devem ainda esquecer-se os múltiplos estudos que desenvolveu no período da formação do direito português moderno e a intervenção relevante que teve em aspectos fulcrais da história do pensamento jurídico nacional.

representou o cumprimento de uma promessa que, seis anos antes, Braga da Cruz formulara no prefácio do primeiro volume.

${ }^{59}$ Impressiona, na verdade, a produção científica e cultural deste Mestre conimbricense. Atesta a sua riqueza a publicação do conjunto da obra de Braga da Cruz que, em boa hora, se decidiu levar a cabo nos «Acta Universitatis Conimbricensis». Constitui uma justa homenagem ao antigo Reitor da Universidade de Coimbra e Director da Biblioteca Geral da Universidade. Saiu a lume, a partir de 1979, sob a designação ampla de Obras Esparsas.

No que toca aos textos de Braga da Cruz no âmbito da regência de direito romano, ver Gonçalo de Sampaio e Melo, Apontamentos para a História do Ensino do Direito Romano em Portugal, cit., vol. 1, pp. 313 e ss. Realçando o papel pioneiro de Braga da Cruz para a história do periodismo jurídico português, destaca-se Rafael Gilbert, Braga da Cruz, "Cien anos de Historia del Derecho Português", in Anuário de Historia del Derecho Espanhol, tomo XLIX (1979), pp. 703 e ss., em particular, pp. 706 e ss.

${ }^{60}$ Acerca de Guilherme Braga da Cruz, consultar, especialmente, Mário Júlio de Almeida Costa, "Um Homem que se chamou Guilherme Braga da Cruz", in «História do Direito e Ciência Jurídica. Homenagem póstuma a Guilherme Braga da Cruz», Porto, 1979, pp. 81 e ss.; Martim de Albuquerque, Elogio do Prof. Doutor Guilherme da Cruz, Lisboa, 1985; Francisco Lucas Pires, "Braga da Cruz, a Universidade, o Direito e a História", in «Guilherme Braga da Cruz. Um homem para a Eternidade», Braga, 1981, pp. 61 e ss.; e Rui de Figueiredo Marcos, A presença de Guilherme Braga da Cruz, in «Depoimentos. Guilherme Braga da Cruz 1916-1977», Coimbra 2006, pp. 349 e ss.

${ }^{61}$ Almeida Costa doutorou-se em Dezembro de 1957 e, em Maio de 1962, já era professor catedrático da Faculdade de Direito da Universidade de Coimbra.

${ }^{62}$ Vide Mário Júlio de Almeida Costa, Origem da Enfiteuse no Direito Português, Coimbra, 1957; do mesmo autor, Raízes do Censo Consignativo. Para a História do Crédito Medieval Português, Coimbra, 1961. 
À semelhança de Braga da Cruz, nunca se confinou à aridez de uma seca exegese das fontes, desarreigada de laços culturais que envolviam os temas pesquisados. Pelo contrário, a ênfase simultânea que, pertinazmente, atribui aos valores e ao teor contextual para melhor apreender a problemática em foco timbrou, a cada passo, a sua própria intenção metódica. Pertence a Almeida Costa o indiscutível mérito de haver trazido a história do direito até aos nossos dias. Abeirou-a do presente e nessa medida aproximou-a de estudantes e de juristas.

Correram mais de duas décadas sobre a primeira edição da História do Direito Português de Almeida Costa, onde esse objectivo de vanguarda logo se cumprira. Um manual que o esmero do autor condenou ao sucesso ${ }^{63}$. A finura ática da exposição, a profundidade das concepções sem prejuízo da clareza das ideias e a cintilância das sínteses elaboradas dotaram a disciplina de enorme força atractiva ${ }^{64}$.

Pela lente da história do direito, engrandeceu-se o relacionamento fecundo da Faculdade de Letras com a Faculdade de Direito ao longo do séc. XX. E sem espanto algum. Muito do que é direito explica-se, genética e funcionalmente, por aquilo que não o é. O direito não irrompe por actos solitários de génio, nem desaparece, fugidiamente, na noite do acaso. Bem vistas as coisas, os laços que prendem o direito à existência cultural e histórica do homem são os mesmos que afeiçoaram os juristas de Coimbra à sua Faculdade de Letras.

Recebido em/Text submitted on: 13/05/2011

Aceite em/Approved on: 18/07/2011

${ }^{63}$ Actualmente vai na quinta edição. Contou com a colaboração de Rui Manuel de Figueiredo Marcos. (Coimbra, Almedina, 2011).

${ }^{64}$ Acerca dos rumos prospectivos da história do direito, ver, na literatura jurídica mais recente, a obra Histoire de l'Histoire du Droit, Textes réunis par Jacques Poumarède, Presses da l'Université des Sciences Sociales de Toulouse, 2006. 